\title{
Morphological Characteristics of Araceae Plants in Liwa Botanical Garden, West Lampung
}

\author{
Risa Suryani Wilyasari*, Yulianty, Zulkifli, Endang Nurcahyani \\ Jurusan Biologi, Fakultas Matematika dan Ilmu Pengetahuan Alam Universitas Lampung \\ Jl. Prof. Soemantri Brodjonegoro, No 1, Bandar Lampung 35145 \\ *Email: Suryanirisa234@gmail.com
}

\begin{abstract}
Araceae is one type of plant that has a fairly high level of diversity and also rich in benefits such as a source of food, ornamental plants, and medicine. Research on the characteristics of Araceae in Indonesia is still limited. The purpose of this study was to identify Araceae plants based on morphological structure and analyze the morphological characteristics of Araceae in Liwa Botanical Garden, West Lampung. This research was conducted from November 2019 to January 2020. Data were collected at Liwa Botanical Garden, West Lampung based on exploration and observation collection methods. Morphological structure data were analyzed as descriptive and qualitative. The parts of plants that are compared between Araceae plants are the shape, size of leaves, petiole, and inflorescences. Observations show that 21 genera Araceae are consisting of 26 plants. Araceae plants have three different ways of life, namely terrestrial, epiphytic, and aquatic. The shape of the leaves is ovatus, cordatus, lanceolatus, cuneatus, needle, peltatus, sagittatus, hastatus, palmatisect, bipinnatisect and tripinnatisect. The characteristics of this plant have compound interest with cob types (spadix) which are covered by a spathawith two types of inflorescences, namely unisexual and bisexual.
\end{abstract}

Keywords: araceae identification, Liwa Botanical Garden

\section{PENDAHULUAN}

Indonesia merupakan salah satu negara kepulauan yang memiliki kekayaan sumber daya alam yang berlimpah baik di daratan maupun di perairan. Menurut Syahdat (2006), Indonesia dikenal sebagai negara dengan keanekaragaman hayati tertinggi kedua setelah Brazil sehingga disebut negara megabiodiversity. Salah satu suku tanaman yang banyak dijumpai berupa tumbuhan suku talas-talasan (Araceae).

Suku Araceae terdiri atas 110 marga, yang meliputi 3.200 jenis. Penelitian mengenai karakteristik Araceae di Indonesia masih terbatas, sedangkan Indonesia memiliki tingkat keanekaragaman Araceae yang tinggi. Kurangnya informasi mengenai manfaat
Araceae menyebabkan masyarakat tidak berminat dan tidak melakukan budidaya tanaman yang termasuk suku Araceae. Kajian mengenai karakteristik Araceae perlu dilakukan untuk mengetahui karakter yang dimiliki tumbuhan Araceae (Khalisa, 2017).

Penelitian ini bertujuan untuk mengidentifikasi tumbuhan suku talastalasan (Araceae) berdasarkan struktur morfologi dan membandingkan karakter morfologi tumbuhan suku talas-talasan (Araceae) di Kebun Raya Liwa, Lampung Barat.

\section{METODE PENELITIAN}

Waktu dan Tempat Penelitian

Penelitian ini dilaksanakan pada bulan November 2019 sampai dengan Januari 
2020 di Kebun Raya Liwa, Kabupaten Lampung Barat yang berlokasi di Desa Pekon Kubu Perahu, Kecamatan Balik Bukit, Liwa Kabupaten Lampung Barat. Penelitian dilakukan secara bertahap yang meliputi pengambilan sampel dan identifikasi tumbuhan. Identifikasi jenisjenis tumbuhan Araceae dilakukan di Laboratorium Botani Jurusan Biologi Fakultas Matematika dan IImu Pengetahuan Alam, Universitas Lampung.

\section{Alat dan Bahan}

Alat yang digunakan dalam penelitian ini adalah alat tulis, alat dokumentasi, gunting, tali, pembolong kertas, meteran, kertas laminating, label atau etiket, penggaris, dan plastik koleksi. Bahan yang digunakan adalah tumbuhan suku Araceae yang terdapat di lokasi penelitian.

\section{Deskripsi Lokasi Penelitian}

Kebun Raya Liwa merupakan salah satu tujuan ekowisata terletak di Pekon Kubu Perahu Kecamatan Balik Bukit Kabupaten Lampung Barat, Provinsi Lampung dengan luas wilayah 86,68 ha. Secara geografis Kebun Raya Liwa terletak antara $5^{\circ}$ 02' 17.89" LS dan $104^{\circ}$ 04' $34.27^{\prime \prime}$ BT dengan curah hujan tahunan rata-rata 2500-3000 $\mathrm{mm}$, bulan basah 7-9 bulan, kisaran suhu $17-30^{\circ} \mathrm{C}$, kelembaban relatif 50\%-80\%, intesitas matahari $37,9 \%$ dan terletak pada ketinggian 800-900 m dpl dengan tapak bergelombang serta kemiringan lereng cukup terjal. Secara administrasi Kebun Raya Liwa di sisi sebelah barat berbatasan dengan kawasan ekowisata Kubu Perahu Resort Balik Bukit, Taman Nasional Bukit Barisan Selatan (TNBBS) dengan objek wisata berupa air terjun Sepapah (Sukimin, 2018).

\section{Cara Kerja}

\section{Identifikasi Tumbuhan Araceae}

Identifikasi tumbuhan dilakukan dengan membandingkan tumbuhan Araceae yang diamati dengan buku identifikasi tumbuhan Araceae. Identifikasi tumbuhan Araceae dilakukan pengukuran pada helaian daun dan panjang tangkai daun menggunakan penggaris dan meteran. Pengamatan bentuk daun dilakukan pencocokan dan perbandingan tipe-tipe helaian daun Araceae berdasarkan buku identifikasi Araceae (Mayo et al., 1997).

Perbungaan pada tumbuhan Araceae dilakukan dengan pengamatan tipe bunga uniseksual atau biseksual berdasarkan bentuk tongkol (spadix) dan seludang bunga (spatha) serta warna bunga.

\section{Pengambilan Sampel}

Pengambilan sampel dilakukan dengan metode jelajah/ eksplorasi (Cruise Method). Sampel yang diambil adalah tumbuhan Araceae yang ditemukan disepanjang daerah jelajah pada saat penelitian.

\section{Pengolahan Data}

Data-data tumbuhan Araceae yang diperoleh dari Kebun Raya Liwa, Lampung Barat diolah secara kualitatif dengan mendeskripsikan jenis-jenis tumbuhan Araceae yang ditemukan di Kebun Raya Liwa, Lampung Barat.

\section{HASIL DAN PEMBAHASAN}

Berdasarkan hasil penelitian di Kebun Raya Liwa, desa Kubu Perahu, Kecamatan Balik Bukit, Kabupaten Lampung Barat diperoleh 21 marga yaitu Acorus, Aglaonema, Alocasia, Amorphophallus, Anthurium, Apoballis, Caladium, Colocasia, Dieffenbachia, Epipremnum, Homalomena, Lasia, Philodendron, Pistia, Pothos, Rhapidophora, Schismatoglottis, Scindapcus, Spathyphyllum, Syngonium, dan Xanthosoma (Tabel 1). Perbungaan jenis-jenis tumbuhan Araceae yang ditemukan di Kebun Raya Liwa, Lampung Barat (Tabel 3).

Karakteristik Morfologi Jenis-Jenis Tumbuhan suku Araceae yang ditemukan di Kebun Raya Liwa Kecamatan Balik Bukit, Lampung Barat Marga dan Jenis- Jenis Araceae yang ditemukan selama penelitian di Kebun Raya Liwa dapat dilihat pada Tabel 1. 
Tabel 1. Marga dan Jenis-Jenis Tumbuhan Araceae yang ditemukan di Kebun Raya Liwa, Lampung Barat

\begin{tabular}{|c|c|c|c|}
\hline No & Marga & Jenis & Cara Hidup \\
\hline 1. & Acorus & Acorus calamus $\mathrm{L}$. & Aquatik \\
\hline 2. & Aglaonema & $\begin{array}{l}\text { 1. Aglaonema crispum } \mathrm{L} \text {. } \\
\text { 2. Aglaonema pictum tricolor (Roxb.) } \\
\text { Kunth }\end{array}$ & $\begin{array}{l}\text { Terestrial } \\
\text { Terestrial }\end{array}$ \\
\hline 3. & Alocasia & Alocasia zebrina Schott. & Terestrial \\
\hline 4. & Amorphophallus & $\begin{array}{l}\text { 1. Amorphophallus muelleri Bl. } \\
\text { 2. Amorphophallus paenifolius (Dennts.) } \\
\text { Nicolson }\end{array}$ & $\begin{array}{l}\text { Terestrial } \\
\text { Terestrial }\end{array}$ \\
\hline 5. & Anthurium & $\begin{array}{l}\text { 3. Amorphophallus titanum Bl. } \\
\text { 1. Anthurium adreanum Schott. } \\
\text { 2. Anthurium cordatum Schott. }\end{array}$ & $\begin{array}{l}\text { Terestrial } \\
\text { Terestrial }\end{array}$ \\
\hline 6. & Apoballis & Apoballis mutata Hook.f. & Terestrial \\
\hline 7. & Caladium & Caladium bicolor Vent. & Terestrial \\
\hline 8. & Colocasia & 1. Colocasia esculenta (L.) Schott. & Terestrial \\
\hline & & 2. Colocasia gigantea (BI.) Hook.f. & Terestrial \\
\hline $\begin{array}{l}9 . \\
10 .\end{array}$ & $\begin{array}{l}\text { Dieffenbacia } \\
\text { Epipremnum }\end{array}$ & $\begin{array}{l}\text { Dieffenbacia seguine (Jacq.) Schott. } \\
\text { Epipremnum silvaticum Schott. }\end{array}$ & $\begin{array}{l}\text { Terestrial } \\
\text { Epifit }\end{array}$ \\
\hline $\begin{array}{l}11 . \\
12 . \\
13 . \\
14 . \\
15 . \\
16 . \\
17 . \\
18 .\end{array}$ & $\begin{array}{l}\text { Homalomena } \\
\text { Lasia } \\
\text { Philodendron } \\
\text { Pistia } \\
\text { Pothos } \\
\text { Rhapidophora } \\
\text { Schismatoglottis } \\
\text { Scindapsus }\end{array}$ & $\begin{array}{l}\text { Homalomena rubescens (Roxb.) Kunth. } \\
\text { Lasia spinosa } \mathrm{L} \text {. } \\
\text { Philodendron marble } \mathrm{L} \text {. } \\
\text { Pistia stratoites } \mathrm{L} \text {. } \\
\text { Pothos scandens } \mathrm{L} \text {. } \\
\text { Rhapidophora korthalsii Schott. } \\
\text { Schismatoglottis calyptrata Zoll \& Moritzi } \\
\text { Scindapsus parakensis Hook.f. }\end{array}$ & $\begin{array}{l}\text { Terestrial } \\
\text { Aquatik } \\
\text { Terestrial } \\
\text { Aquatik } \\
\text { Epifit } \\
\text { Epifit } \\
\text { Terestrial } \\
\text { Epifit }\end{array}$ \\
\hline $\begin{array}{l}19 . \\
20 . \\
21 .\end{array}$ & $\begin{array}{l}\text { Spathiphyllum } \\
\text { Syngonium } \\
\text { Xanthosoma }\end{array}$ & $\begin{array}{l}\text { Spathiphyllum wallisii } \mathrm{L} . \\
\text { Syngonium podophylum Schott. } \\
\text { Xanthosoma violaceum L. }\end{array}$ & $\begin{array}{l}\text { Terestrial } \\
\text { Epifit } \\
\text { Terestrial }\end{array}$ \\
\hline
\end{tabular}

Dari hasil penelitian ditemukan 26 jenis tumbuhan Araceae di Kebun Raya Liwa dengan cara hidup yang berbeda. Pada Tabel 1 dapat diketahui terdapat 17 jenis tumbuhan Araceae yang memiliki cara hidup terestrial, 5 jenis memiliki cara hidup epifit, dan 3 jenis lainnya memiliki cara hidup aquatic. Jenis Araceae dari marga Amorphophallus paling banyak ditemukan di Kebun Raya Liwa dibandingkan dengan marga lainnya. Ukuran daun pada masing- masing jenis Araceae yang ditemukan di Kebun Raya Liwa dapat dilihat pada Tabel 2.

Bentuk-bentuk daun yang ditemukan pada tumbuhan Araceae adalah bulat telur, jantung, lanset, segitiga terbalik, jarum, perisai, anak panah, bertakuk, bertakuk menyirip, dan bertakuk 3 menyirip. Jenis Araceae yang memiliki bentuk daun lanset lebih banyak dibandingkan bentuk daun lainnya. Ukuran daun terbesar terdapat pada Amorphophallus tittanum Bl. dengan ukuran panjang mencapai $60 \mathrm{~cm}$ dan lebar mencapai $37 \mathrm{~cm}$ sedangkan daun yang terkecil adalah daun Pistia stratoites $L$. yang memiliki ukuran panjang daun hanya $9 \mathrm{~cm}$ dan lebar mencapai 6 $\mathrm{cm}$.

Adapun tipe perbungaan pada jenis- jenis Araceae yang ditemukan di Kebun Raya Liwa dapat dilihat pada Tabel 3 . Perbedaan jenis tumbuhan Araceae dapat dilihat dari struktur morfologi seperti ukuran dan bentuk daun dan karakter perbungaan (Dian et al., 2017). Perbungaan tumbuhan Araceae tersusun dalam bentuk tongkol (spadix) yang diselubungi oleh seludang (spatha). Menurut Mayo et al., (1997) karakter perbungaan pada tumbuhan Araceae dikelompokkan ke dalam tipe perbungaan 
Tabel 2. Parameter morfologi daun tumbuhan Araceae

\begin{tabular}{|c|c|c|c|c|}
\hline No & +2 & Bentuk daun & $\begin{array}{l}\text { Panjang daun } \\
\text { (cm) }\end{array}$ & $\begin{array}{l}\text { Lebar daun } \\
(\mathrm{cm})\end{array}$ \\
\hline 1. & Acorus calamus L. & Jarum & $19-33$ & $0,5-1$ \\
\hline 2. & Aglaonema crispum L. & Lanset & $8-22$ & $3-9$ \\
\hline 3. & $\begin{array}{l}\text { Aglaonema pictum tricolor (Roxb.) } \\
\text { Kunth. }\end{array}$ & Lanset & $10-15$ & $4-7$ \\
\hline 4. & Alocasia zebrina Schott. & Perisai & $23-63$ & $13-40$ \\
\hline 5. & Amorphophallus muelleri $\mathrm{BI}$. & Bertakuk & $10-15$ & $7-14$ \\
\hline 6. & $\begin{array}{l}\text { Amorphophallus paenifolius } \\
\text { (Dennts.) Nicolson }\end{array}$ & $\begin{array}{l}\text { Bertakuk } \\
\text { menyirip }\end{array}$ & $12-26$ & $10-18$ \\
\hline 7. & Amorpophallus tittanum $\mathrm{Bl}$. & $\begin{array}{l}\text { Bertakuk } 3 \\
\text { menyirip }\end{array}$ & $40-78$ & $24-47$ \\
\hline 8. & Anthurium andreanum Schott. & Jantung & $15-25$ & $8-15$ \\
\hline 9. & Anthurium cordatum Schott. & Jantung & $12-21$ & $5-13$ \\
\hline 10. & Apoballis mutata Hook.f. & Lanset & $20-30$ & $9-14$ \\
\hline 11. & Caladium bicolor Vent. & Perisai & 3-22 & $17-22$ \\
\hline 12. & Colocasia esculenta (L.) Schott & Perisai & $10-43$ & $7-29$ \\
\hline 13. & Colocasia gigantea (BI.) Hook.f. & Jantung & $12-75$ & $6-36$ \\
\hline 14. & $\begin{array}{l}\text { Dieffenbachia seguine (Jacq.) } \\
\text { Schott. }\end{array}$ & $\begin{array}{l}\text { Bulat telur } \\
\text { memanjang }\end{array}$ & $10-21$ & $5-7$ \\
\hline 15. & Epipremnum silvaticum Schott. & Lanset & $15-22$ & $4-6$ \\
\hline 16. & $\begin{array}{l}\text { Homaloemena rubescens (Roxb.) } \\
\text { Kunth. }\end{array}$ & Jantung & $10-23$ & $5-19$ \\
\hline 17. & Lasia spinosa L. & Tombak & 23- 52 & $4-42$ \\
\hline 18. & Philodendron marble L. & Lanset & $21-32$ & 14- 18 \\
\hline 19. & Pistia stratiotes L. & $\begin{array}{l}\text { Segitiga } \\
\text { terbalik }\end{array}$ & $2-9$ & $1-6$ \\
\hline 20. & Pothos scandensi L. & Bulat telur & $7-12$ & 2- 4 \\
\hline 21. & Raphidophora korthalsii Schott. & Bulat telur & 3-11 & $1-6$ \\
\hline 22. & $\begin{array}{l}\text { Schismatoglottis calyprata Zoll. \& } \\
\text { Moritzi }\end{array}$ & Anak panah & $15-18$ & $4-10$ \\
\hline 23. & Scindapcus perakensis Hook.f. & Jantung & $7-10$ & $3-8$ \\
\hline 24. & Spathiphyllum wallisii L. & Lanset & $20-42$ & $9-12$ \\
\hline 25. & Syngonium podophyllum Schott. & Anak panah & $18-25$ & $3-7$ \\
\hline 26. & Xanthosoma violaceum $\mathrm{L}$. & Anak panah & $20-45$ & $15-43$ \\
\hline
\end{tabular}

biseksual dan uniseksual. Amorphophallus tittanum Bl. memiliki ukuran daun lebih besar dibandingkan Amorphophallus paenifolius (Dennst.) Nicolson. Namun pada kedua tanaman tersebut jumlah percabangan daun tidak berbeda. Sedangkan pada Amorphophallus paenifolius (Dennst.) Nicolson memiliki bentuk lebih kecil dibandingkan dengan Amorphophallus muelleri Bl. Salah satu jenis tumbuhan Araceae aquatik yang ditemukan di Kebun Raya Liwa adalah Pistia stratiotes L. Tumbuhan ini dapat mengapung bebas di atas permukaan air dan memiliki susunan perbungaan yang terdiri dari seludang dan tongkol. Permukaan daun Pistia stratiotes L. mempunyai bulu-bulu halus berfungsi untuk memerangkap gelembung udara sehingga memungkinkan $P$. stratiotes L. untuk mengapung di atas permukaan air (Neuenschwander et al., 2009).

Salah satu jenis tumbuhan Araceae aquatik yang ditemukan di Kebun Raya Liwa adalah Pistia stratiotes L. Tumbuhan ini mempunyai bentuk daun segitiga terbalik (cuneatus) dan pertulangan daun sejajar. Permukaan daun $P$. stratiotes mempunyai bulu-bulu halus yang menutupi seluruh permukaan daun (Khoirul, 2014). Berdasarkan hasil pengamatan yang dilakukan bahwa tumbuhan Araceae aquatik di Kebun Raya Liwa terdiri atas 3 marga yaitu Pistia stratiotes L., Acorus calamus L., dan Lasia spinosa L. 
Epipremnum silvaticum Schott memiliki ciri khas terdapat bagian yang menonjol berwarna coklat pada tangkai daunnya. Shu et al., (2010) menyatakan bahwa $E$. silvaticum Schott memiliki tangkai daun dengan adanya pulvinus yang terletak pada bagian dekat dengan daun. Menurut Mayo et al., (1997) pulvinus atau pembengkakan yang terletak di ujung tangkai daun dapat ditemukan hampir pada semua kelompok Pothoideae, Monsteroideae dan beberapa Aroideae.

Rhaphidophora korthalsii Schott yang ditemukan memiliki ciri khas pada batang yang berbentuk persegi dan berwarna hijau. Menurut Kurniawan et al., (2012) Rhaphidophora memiliki keunikan pada batang yang berbentuk persegi, berbukubuku sedikit rapat dan bentuk daun bulat telur-lanset (ovatus-lanceolatus), tebal dan kaku.

Tabel 3. Karakteristik perbungaan yang ditemukan di Kebun Raya Liwa, Lampung Barat

\begin{tabular}{lll}
\hline No. & \multicolumn{1}{c}{ Jenis Araceae } & Tipe Perbungaan \\
\hline 1. & Acorus calamus L. & Uniseksual \\
2. & Aglaonema crispum L. & Uniseksual \\
3. & Aglaonema pictum tricolor (Roxb.) Kunth. & Uniseksual \\
4. & Alocasia zebrina Schott. & Uniseksual \\
5. & Amorphophallus muelleri BI. & Uniseksual \\
6. & Amorphophallus paenifolius (Dennst.) Nicolson & Uniseksual \\
7. & Amorphophallus tittanum Bl. & Uniseksual \\
8. & Anthurium adraeanum Schott. & Uniseksual \\
9. & Aphoballis mutata Hook. f. & Uniseksual \\
10. & Anthurium cordatum Schott. & Uniseksual \\
11. & Caladium bicolor Vent. & Uniseksual \\
12. & Colocasia esculenta (L.) Schott. & Uniseksual \\
13. & Colocasia gigantea (BI.) Hook.f. & Uniseksual \\
14. & Dieffenbacia seguine (Jacq.) Schott. & Uniseksual \\
15. & Epipremnum silvaticum Schott. & Biseksual \\
16. & Homalomena rubescens (Roxb.) Kunth. & Uniseksual \\
17. & Lasia spinosa L. & Uniseksual \\
18. & Philodendron marble L. & Uniseksual \\
19. & Pistia stratoites L. & Uniseksual \\
20. & Pothos scandens L. & Biseksual \\
21. & Rhapidophora korthalsii Schott. & Biseksual \\
22. & Schismatoglottis calyptrata Zoll \& Moritzi & Uniseksual \\
23. & Scindapsus perakensis Hook.f. & Biseksual \\
24. & Spathiphyllum wallisii L. & Uniseksual \\
25. & Syngonium podophylum Schott. & Biseksual \\
26. & Xanthosoma violaceum Schott. & Uniseksual \\
& &
\end{tabular}

Dari penelitian yang telah dilakukan, ditemukan jenis Araceae dengan bentuk daun seperti anak panah (sagittatus), misalnya pada Alocasia zebrina Schott dan Syngonium podophyllum Schott, bentuk daun jantung (cordatus) pada Colocasia esculenta Schott, bentuk daun perisai (peltatus) pada Caladium bicolor Vent, bentuk daun lanset (lanceolatus) pada Epipremnum silvaticum Schott dan Rhaphidophora korthalsii Schott, bentuk daun bulat telur (ovatus) pada Scindapsus perakensis Hook.f. Menurut Kurniawan et al., (2012) Araceae memiliki bentuk, pola, warna dan ukuran yang bervariasi dari ukuran kecil hingga berukuran besar dari bentuk sederhana, seperti berbentuk perisai (peltatus), bulat telur (ovatus), dan anak panah (sagittatus) hingga kompleks, seperti berbentuk bertakuk menyirip pada Amorphophallus.

\section{KESIMPULAN}

Berdasarkan penelitian yang dilakukan dapat disimpulkan bahwa tumbuhan Araceae di Kebun Raya Liwa, Lampung Barat diperoleh 21 marga terdiri dari 26 jenis tumbuhan Araceae. Tumbuhan Araceae memiliki dua tipe perbungaan 
yakni uniseksual dan biseksual dengan tiga cara hidup berbeda yaitu terestrial, epifit, dan aquatik dengan bentuk daun berupa bulat telur, lanset, anak panah, jantung, tombak, segitiga terbalik, bertakuk, bertakuk menyirip dan bertakuk 3 menyirip. Beberapa tangkai daun tumbuhan Araceae memiliki ciri khusus bercorak, bertotol- totol dan merambat.

\section{UCAPAN TERIMAKASIH}

Kegiatan penelitian ini merupakan bagian dari kegiatan kerjasama antara Jurusan Biologi FMIPA Unila dengan Kebun Raya Liwa Lampung Barat.

\section{DAFTAR PUSTAKA}

Dian N. W., Mukarlina., dan T. Masnur. (2017). Inventarisasi Tumbuhan Araceae Di Hutan Desa Subah Kecamatan Tayan Hilir Kabupaten Sanggau Kalimantan Barat. Protobiont (2017). 6 (3) : 207 214.

Khalisa, A. S., Murningsih dan Jumari. (2017). Identifikasi Talas- Talasan Edible (Araceae) Di Semarang, Jawa Tengah. Universitas Diponegoro. Jurnal Penelitian Departemen Biologi Fakultas Sains dan Matematika 19 (1) : 18-21.

Khoirul, B. (2014). Identifikasi Tanaman Famili Araceae Di Cagar Alam Tangale Kabupaten Gorontalo.Tesis. Universitas Negeri Gorontalo.
Kurniawan, A, Warseno dan Asih, N.P.S. (2012). Araceae Di Pulau Bali, UPT Balai, Konservasi Tumbuhan Kebun Raya Eka Karya, Bali, Lembaga IImu Pengetahuan Indonesia (LIPI). LIPI Press. Jakarta.

Neuenschwander, P, Julien, MH, Ted D. Center, \& Martin P. Hill. (2009). Pistia stratiotes L. (Araceae), Biological Control of Tropical Weeds using Arthropods, ed. R. Muniappan, G. V. P. Reddy.

Shu, QLY, Heng, L., dan Boyce, PC. (2010). Epipremnum Schott, Bonplandia (Hannover) 5:45, 1857. Flora Of China Vol 23, hal. 14-15.

Sukimin., dan S.M. Sholihah. (2018). Warta Kebun Raya.Pusat Konservasi Tumbuhan Kebun Raya Lembaga Ilmu Pengetahuan Indonesia. Bogor.

Syahdat, E. (2006).Kajian Pedoman Penatausahaan Hasil Hutan di Hutan Raya Sebagai Dasar Acuan Pemanfaatan Hutan Raya.Jurnal Penelitian Sosial dan Ekonomi Kehutanan. Vol 3 (1) : 46-48.

Mayo, J. S., Bogner J. and. Boyce, P.C. (1997). The Genera of Araceae.The European Union: Continental Printing, Belgium. 

